\title{
Morbidity and mortality predictors of septic shock in children
}

\author{
Rabindran', Gedam DS ${ }^{2}$ \\ ${ }^{1}$ Dr. Rabindran, Consultant Neonatologist, Billroth Hospital, Chennai; ${ }^{2}$ Dr D Sharad Gedam, Professor of Pediatrics, \\ L.N. Medical College, Bhopal, MP, India
}

Address for Correspondence: Dr Rabindran, E-mail: rabindranindia@yahoo.co.in

\begin{abstract}
Lactate is the most commonly used predictor in septic shock. High lactate levels are associated with increased mortality. Septic shock is the most common type of shock with around 50\% mortality. Mortality increases by nearly $40 \%$ with every hour of delayed treatment.
\end{abstract}

Keywords: Septic shock, Predictors, Biomarkers

Septic shock is the most common type of shock with around $50 \%$ mortality. Mortality increases by nearly $40 \%$ with every hour of delayed treatment. Knowing factors affecting outcome will help in early recognition, timely therapeutic changes \& better outcome. There are many factors that predict mortality \& morbidity of septic shock like Serum lactate, Absolute Neutrophil count, Procalcitonin, BNP, cTnT assay, Inflammatory mediators, D-dimer levels, Vaso-active inotrophic score, Shock index, VEGF, Gastric tonometry, Biomarkers, Risk models, Transmembrane glycoproteins, Repression of gene programs, NMR metabolite profiling, Pentraxin, pro-vasopressin, Proadrenomedullin \& Quantitative metabolomics.

Lactate is the most commonly used predictor in septic shock. High lactate levels are associated with increased mortality. Unlike in sepsis where increased lactate (stress lactate) represents increased glycolytic flux secondary to hypermetabolism; in septic shock, increased lactate (shock lactate) is due to glycolytic flux secondary to tissue hypoxia [1]. Lactate has a better prognostic value in septic shock compared to Tumour Necrosis Factor (TNF) \& Interleukin-6 \& survival improved in those in whom lactate decreased within $1 \mathrm{~h}$ after resuscitation. However recently American College of Critical Care Medicine (ACCM) guidelines have cautioned against routine lactate monitoring in septic shock, as epinephrine infusion increases plasma lactate independent of changes in organ perfusion [2]. Absolute Neutrophil Count (ANC) is a simple test that can be used as a predictor of impending septic shock. Incidence of septic shock in those with ANC < $1500 / \mathrm{mm}^{3}$ was greater compared to those with $\mathrm{ANC} \geq$ $1500 / \mathrm{mm}^{3}(\mathrm{p}=0.015$; odds $=6.333)[3]$. Procalcitonin (PCT) is another useful marker which has a better discriminative power to predict septic shock \& mortality compared to CRP \& lactate. Markers like Brain Natriuretic Peptide (BNP; cutoff 49pg/ml) \& Cardiac Troponin $\mathrm{T}$ (cTnT) assay has been recently studied as sensitive predictors of mortality in septic shock. Pro-inflammatory mediators like IL-6, IL-8 \& MCP-1, as well as immunosuppressive cytokine like IL10 have been studied to be significantly associated with increased mortality in septic shock. IL-8 $<220 \mathrm{pg} / \mathrm{ml}$ predicts with $95 \%$ accuracy survival of children with septic shock \& level $>220 \mathrm{pg} / \mathrm{ml}$ had $75 \%$ sensitivity for predicting deaths[4].CD11b expression on neutrophils predicts organ failure in septic shock. Elevated D-dimer level is associated with death\& declining levels are associated with positive response to therapy. High mottling score \& tissue oxygen saturation also accurately predicted mortality in septic shock. Vasoactive-Inotropic Score (VIS) is an objective bedside hemodynamic parameter to monitor cardiovascular support in septic shock\& high VIS is associated with poor clinical outcome in children with fluid-refractory septic shock.

Shock Index (Heart rate / Systolic blood pressure) has been shown to be a clinical predictor of mortality in children with septic shock. Endothelin mediators like VEGF \& sFLT when deranged are associated with increased mortality \& prolonged hospitalization.

Use of gastric tonometry in pediatric septic shock appears to distinguish survivors from nonsurvivorswith a sensitivity of $67 \%$, specificity of $74 \%$, PPV of $52 \%$ in predicting mortality. The mean $\mathrm{pHi}$ in non survivors (7.32 \pm 0.18$)$ was significantly lower than that in survivors (7.48 \pm 0.07$)[5]$. Of late Biomarkers like CCL3, HSPA1B, IL8, ELA2, LCN2, GZMB, MMP8, ang-2 \& IL-13 along with gene probes have been identified using genome-wide expression profiling that helps in prognostication of pediatric septic shock [6]. Biomarker risk models like PERSEVERE(pediatricsepsis biomarker risk model) reliably predicts mortality in children with septic shock. Three biomarkers (CCL3, HSPA1B \& IL8) appear to be primary predictors in PERSEVERE with a sensitivity for mortality of $93 \%$, specificity $74 \%$, PPV $32 \% \&$ NPV 99\%. When applied to cohort of septic shock 
children, those predicted as non-survivors had $>25 \%$ mortality by 28 days. Moreover high-risk survivors had greater degree of illness severity like persistence of organ failure \& prolonged hospitalisation.TREM-1 is a transmembrane glycoprotein that triggers an inflammatory response. Its soluble fraction (sTREM-1) has an excellent predictive value for septic shock/death. sTREM-1 $>300 \mathrm{pg} / \mathrm{mL}$ correctly predicted progression to septic shock, with a sensitivity of $78 \% \&$ a specificity of $97 \%[7]$.

Pediatric septic shock is characterized by widespread repression of gene programs corresponding to various major components of adaptive immune system, including $\mathrm{T}$-cell receptor signaling pathway, $\mathrm{T}$-cell function, B-cell function \&major histocompatibility complex antigen presentation pathway. Gene repression is evident within first $24 \mathrm{~h}$ of presentation of septic shock \& persists into third day. MMP-8 is consistently the highest repressed gene in children with septic shock\& its degree \& proteolytic activity positively correlate with severity \&mortality. Newer modalities like nuclear magnetic resonance (NMR) metabolite profiling \& quantitative metabolomics help in prediction of mortality in septic shock. Elevated levels of 2-oxoisocaproate, creatine, creatine phosphate, creatinine, histidine\& phenylalanine are associated with enhanced muscular protein turnover, amino acid oxidation, decreased energy supply\& organ failure during septic shock [8]. Other novel markers like Pentraxin, pro-vasopressin and proadrenomedullin have been studied to be significantly associated with mortality in septic shock [9]. With the advent of latest technology multiple markers are being studied in prediction of outcome of septic shock. With judicious application of these markers along with cautious interpretation, care of children with septic shock can be improved.

\section{Reference}

1. Mizock BA. The hepatosplanchnic area and hyperlactatemia: A tale of two lactates. Crit Care Med. 2001 Feb;29(2):447-9.

2. Di Giantomasso D, Bellomo R, May CN. The haemodynamic and metabolic effects of epinephrine in xperimental hyperdynamic septic shock. Intensive Care Med. 2005 Mar;31(3):454-62. Epub 2005 Feb 15.

3.Lucy Amelia, Idham Jaya Ganda, DasrilDaud, Absolute Neutrophil Count as a Septic Shock Predictor in Pediatric Emergency Room, American Journal of Clinical and Experimental Medicine. Vol. 3, No. 2, 2015, pp. 68-72. doi: 10.11648/j.ajem.20150302.14.

4. Wong HR, Cvijanovich N, Wheeler DS, Bigham MT, Monaco M, Odoms K, Macias WL, Williams MD. Interleukin-8 as a stratification tool for interventional trials involving pediatric septic shock. Am J Respir Crit Care Med.2008 Aug 1;178(3):276-82. doi: 10.1164/rccm.200801-131OC. Epub 2008 May 29.

5.Brian Krafte-Jacobs; Jeannean Carver; James D. Wilkinson.Comparison of Gastric Intramucosal pH and Standard Perfusional Measurements in Pediatric Septic Shock ; Chest. 1995;108(1):220-225. doi:10.1378/chest.108.1.220.

6. Wong HR. Genetics and genomics in pediatric septic shock. Crit Care Med. 2012 May;40(5):1618-26. doi: 10.1097/CCM.0b013e318246b546.

7. Arízaga-Ballesteros V, Alcorta-García MR, LázaroMartínez LC, Amézquita-Gómez JM, Alanís-Cajero JM, Villela L, Castorena-Torres F, Lara-Díaz VJ. Can sTREM-1 predict septic shock \& death in late-onset neonatal sepsis? A pilot study. Int J Infect Dis. 2015 Jan;30:27-32. doi: 10.1016/j.ijid.2014.10.013. Epub 2014 Nov 5.

8. Kovarik M, Muthny T, Sispera L, Holecek M. Effects of $\beta$-hydroxy- $\beta$-methylbutyrate treatment in different types of skeletal muscle of intact and septic rats. J Physiol Biochem. 2010 Dec;66(4):311-9. doi: 10.1007/s13105010-0037-3. Epub 2010 Aug 20.

9. Guignant C, Voirin N, Venet F, Poitevin F, Malcus C, Bohé J, Lepape A, Monneret G. Assessment of provasopressin and pro-adrenomedullin as predictors of 28day mortality in septic shock patients. Intensive Care Med. 2009 Nov;35(11):1859-67. doi: 10.1007/s00134009-1610-5. Epub 2009 Aug 7.

\section{How to cite this article?}

D Manikyamba, A Krishna Prasad, A Satyavani, S Sunil. Clinical profile and complications of acute mal aria caused by different species of Plasmodium. Pediatr Rev: Int J Pediatr Res 2016;3(1):1-2.doi:10.17511/ijpr.2016.101.01 